\title{
Psychosocial safety climate: a multilevel theory of work stress in the health and community service sector
}

\author{
M. F. Dollard* and W. McTernan \\ Work and Stress Research Group, Centre for Applied Psychological Research, University of South Australia, Adelaide, South Australia
}

\begin{abstract}
Work stress is widely thought to be a significant problem in the health and community services sector. We reviewed evidence from a range of different data sources that confirms this belief. High levels of psychosocial risk factors, psychological health problems and workers compensation claims for stress are found in the sector. We propose a multilevel theoretical model of work stress to account for the results. Psychosocial safety climate (PSC) refers to a climate for psychological health and safety. It reflects the balance of concern by management about psychological health $v$. productivity. By extending the health erosion and motivational paths of the Job Demands-Resources model, we propose that PSC within work organisations predicts work conditions and in turn psychological health and engagement. Over and above this, however, we expect that the external environment of the sector particularly government policies, driven by economic rationalist ideology, is increasing work pressure and exhaustion. These conditions are likely to lead to a reduced quality of service, errors and mistakes.
\end{abstract}

Key words: Work stress, psychosocial safety climate, health and community services, job demands-resources model.

Work stress is a significant risk factor for both physical (e.g. cardiovascular disease (CVD); Belkic et al., 2004) and psychological health (e.g. depression; LaMontagne et al., 2008). Stress-related illnesses are forecast to be the leading causes of the global disease burden by 2020 (Murray \& Lopez, 1996). Ecnotech (2008) estimates that stress-related lost productivity costs Australia around $\$ 14.8$ billion annually or $1.78 \%$ of GDP. Similarly, Kessler et al. (2009) estimate that depression, an outcome of work stress, costs more than $\$ 36$ billion annually in the US from the resulting productivity loss.

Occupations in the health and community service sector, such as nursing, social work, medicine, rehabilitation work and welfare work, are widely regarded as stressful (Dollard et al., 2006). In this editorial, we review the evidence for this claim. Firstly, we review current theoretical frameworks that help us describe, explain and predict when, how and why work stress will occur. Then, we examine the commonly identified stressors in the sector. We review the status of interventions for work stress prevention in the sector, and finally we offer a theoretical way forward.

\footnotetext{
* Address for correspondence: Dr Maureen Dollard, Work and Stress Research Group, Centre for Applied Psychological Research, University of South Australia, Adelaide, South Australia.

(E-mail: maureen.dollard@unisa.edu.au)
}

\section{Stress in the health and community service sector}

International reviews of the empirical evidence conclude that the levels of work stress in the health and community services sector are high (Bakker et al., 2000; Michie \& Williams, 2003; Dollard et al., 2007; Kumar, in press). A recent Canadian study of over 77000 participants found workers in the 'nursing and residential care facilities' industry had the eighth highest risk of poor mental health out of 95 industries (Marchand, 2007). Australian workers compensation data corroborates this and shows that the health and community services sector recorded the highest rate of mental stress claims per 100000 employees in 2007-8 (Productivity Commission, 2010).

Using recent interview data from the Australian Workplace Barometer project collected in 2010 from workers aged 18 to 82 from three Australian states, New South Wales, Western Australia and South Australia $(N=3217)$, we compared the health and community services sector with 16 other industry classifications in terms of health risks and psychological health outcomes. (Australian Workplace Barometer project, currently in progress is supported by an Australian Research Council Discovery grant DP087900 awarded to M.F. Dollard, A.H. Winefield, A.D. LaMontagne, A. W. Taylor, A.B. Bakker, C. Mustard Working wounded or engaged? Australian work conditions and consequences through the lens of the Job Demands-Resources Model.) 
Relative to other industries the health and community services sector showed higher levels of known stress risk factors, including emotional demands, harassment, workplace bullying and psychological demands (i.e. work pressure and workload) than other industry sectors. Remarkably these risk factors were significantly higher than nearly every other industry. In terms of psychological health outcomes (i.e. psychological distress, emotional exhaustion and depression), again the level for health and community services sector was high in comparison with other sectors.

Together these results confirm that workers in the health and community services have the highest levels of psychosocial risk and relatively high levels of psychological health problems.

\section{Unifying stress frameworks}

Several work stress theories have been proposed to explain how, when and why work stress occurs. Prevailing dominant work stress theories mainly focus on the work context particularly job design elements (e.g. Job Demands-Control model, Karasek, 1979; Effort-Reward Imbalance model, Siegrist, 1996) as precursors to adverse health and work effects. These theories, in general, have received significant empirical support in the literature. A more recent theory, Job Demands-Resources (JD-R) model (Demerouti et al., 2001), categorises occupational stressors as job demands and job resources. Job demands are 'things that have to be done' and refer to those psychological, physical, social or organisational aspects of the job that require sustained physical and/or psychological effort (Schaufeli \& Bakker, 2004, p. 296). Job resources are physical, psychological, social or organisational aspects of the job that may (a) aid in achieving work goals; (b) reduce job demands and the associated physiological and psychological costs; and (c) stimulate personal growth and learning (Schaufeli \& Bakker, 2004, p. 296). JD-R theory links stressors (demands and resources) to both health problems and positive work behaviour, such as engagement, via two separate psychological process pathways (Bakker \& Demerouti, 2007). The first is a health erosion process (see Fig. 1), whereby efforts to cope with chronic job demands leads to over-taxing and an erosion of a worker's energy reserve leading, in turn, to negative responses (e.g. psychological distress), and in the longer term to psychological injury (e.g. depressive disorder) and health problems (e.g. CVD). The second process is $a$ motivational process such that adequate resources (e.g. control) may be intrinsically and extrinsically motivating leading to engagement and in turn to positive organisational outcomes (e.g. improved performance). The JD-R framework is important because it highlights the interplay between health and performance outcomes.

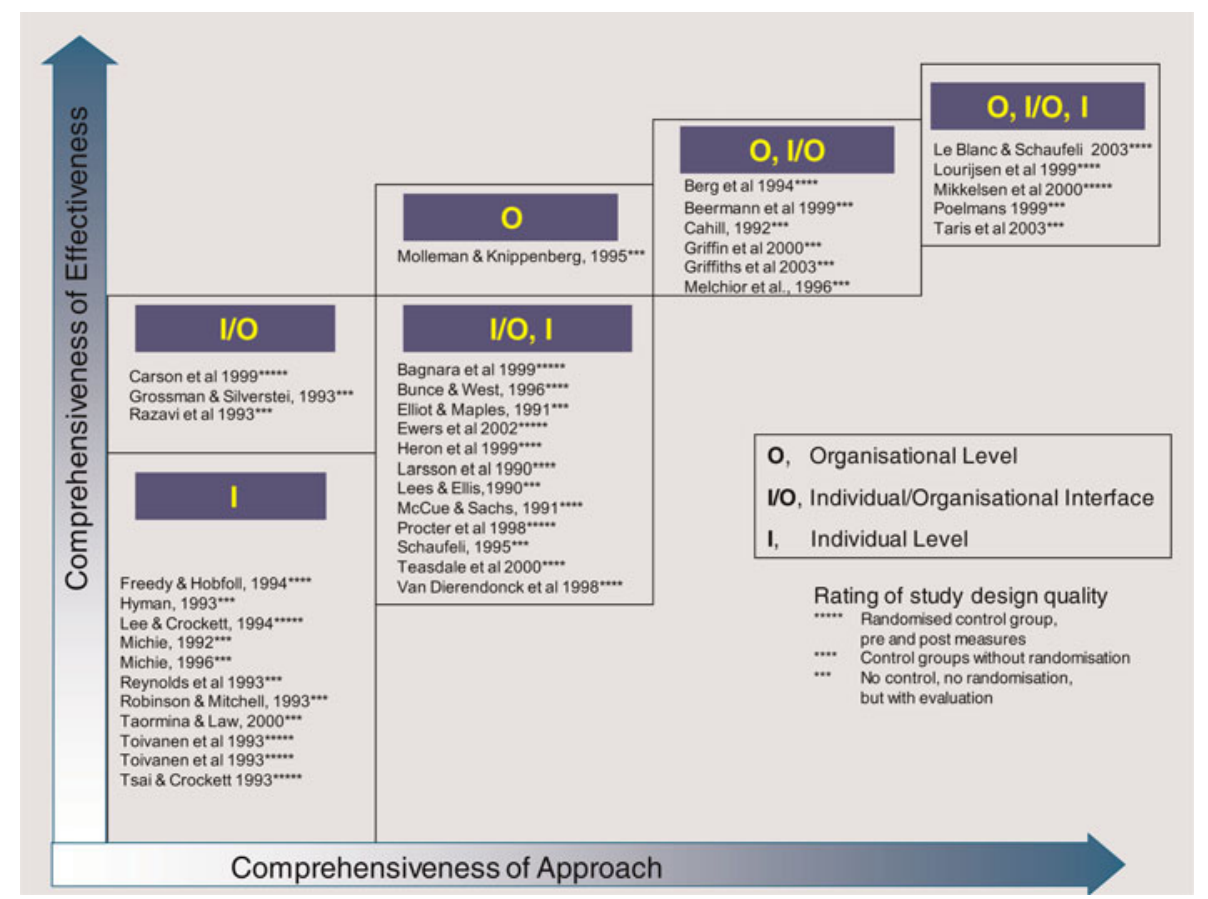

Fig. 1. Stress intervention studies in the health and community services sector 1990-2004. Reproduced with permission from NSW WorkCover [Dollard et al. (2006, p. 43)]. (A colour version of this figure is available online at http://journals.cambridge.org/eps) 


\section{Stressors and strains in the industry}

Several reviews shed light on the most prevalent stressors in the sector because of their associations with adverse health and work outcomes. Michie \& Williams (2003) in a review (1987-1999) of the health care sector, found long work hours, work pressure, work load, lack of participation in decision making, lack of control over work, poor social support, work role and unclear management were the most significant stressors. McVicar (2003) in a review of nursing studies (1985-2003), found workload, leadership management style, emotional demands, lack of rewards, working shifts and professional conflict as the main sources of stress. Dollard et al. (2007) reviewed 35 studies of the health and community services sector (1999-2004), and found that the most common stressors related to quantitative demands (e.g. how much work is required and working hours) as well as qualitative demands (e.g. emotional demands and cognitive demands). Low resources are also identified as stressors in the sector. Dollard et al. found low job control, low support, low rewards, high effort-reward imbalance, role stressors, interpersonal conflict and low organisational justice as major resource factors associated with distress. On balance Dollard et al. (2007) concluded that results were consistent with the JD-R model: high demands combined with low resources were associated with adverse health (e.g. psychological and physical) and organisational impacts (e.g. sickness absence and reduced job satisfaction).

Several stressors warrant special attention because of their profound effect in the sector. Because many workers in the sector are in direct contact with clients, workers may experience a range of taxing emotional demands that may frequently manifest as traumatic and acute stressors, such as violent incidences that arise from working with dangerous or violent clients, child protection traumas or death of a co-worker (Dollard et al., 2007). Violence against health workers is an increasing problem (Brooks et al., 2010) particularly in mental health units and emergency departments (Benveniste et al., 2005; Bowers et al., 2007), ambulance services, drug and alcohol clinics, the agedcare industry (Mayhew \& Chappell, 2003) and among nurses in remote and isolated settings (Opie et al., 2010). Bullying has also been identified as a major stressor in the sector within Australia, possibly emerging from the hierarchical structure of hospitals and the financial strain hospitals in the public sector experience (Mayhew \& Chappell, 2003). The health and community services sector accounted for around $10 \%$ of all employment in Australia yet accounted for $21.6 \%$ of newly accepted mental stress claims in 2007-8, with $24.0 \%$ of all mental stress claims due to bullying/ harassment (Productivity Commission, 2010). There is a clear over-representation of workers compensation claims for the industry in relation to bullying. However, as noted earlier in the Australian Workplace Barometer project, self-reports of being bullied in the sector were the highest. This is important to note because in private, workers are reporting bullying; the observation of high claims is therefore not readily ascribed to a propensity of the sector for workers compensation.

In relation to stress outcomes, the most important outcomes may be surmised from the frequency of research investigation (Dollard et al., 2006). For psychological effects, they are emotional exhaustion, depersonalisation, psychological distress and personal accomplishment. For physiological outcomes, they are physical health and psychosomatic health complaints. For work outcomes, they are job satisfaction and sickness absence. Violence is found to relate to the serious post traumatic stress disorder (Opie et al., 2010). Overall the reviews of work stress in the sector show strong associations between work factors and adverse health and organizational outcomes (Dollard et al., 2006).

\section{Progress in intervention research}

Given the empirical evidence regarding the levels of stress in the sector, researchers have implemented and evaluated interventions to address work-related stress. On the basis of evidence linking work conditions to worker-health outcomes, interventions that focus on modifying the work environment should feature prominently. Researchers evaluated 38 intervention studies (Fig. 1) that were conducted in the health and community services sector (1990-2004) (Dollard et al., 2006). Interventions were classified in terms of their target, the organisation $(\mathrm{O})$, the interface between the person and the organisation $(\mathrm{I} / \mathrm{O})$ or the individual (I). Organisational interventions refer to those that target the organisational climate or the psychosocial and physical work environment. I/O interventions work to build the fit between the individual and the organisation and may involve for example, role clarification or change, training in new systems or management of angry customers. Finally, individual interventions (I) target the individual and are intended to build the individual's capacity to cope with stress. Examples include relaxation training, desensitisation, and cognitive behaviour therapy.

The research found that most interventions in the sector included individual targets $(74 \%)$ or were focused at the individual-organisational interface $(68 \%)$. Far fewer studies targeted organisational factors 
$(32 \%)$, either alone or in combination with other types. Particularly studies including $\mathrm{O}$ approaches, reduced work stressors suggesting that they are not immutable but are amenable to change; those combining various individual level interventions were effective in reducing short-term symptoms. Without even considering the efficacy of the interventions themselves, the evidence suggests that many of these studies are illtargeted (i.e. not focused on work stress sources) and are therefore likely have little effect in the long term for reducing stress. The most beneficial intervention is likely to embrace a combination of targets.

\section{The genesis of new theory - psychosocial safety climate (PSC) work stress theory}

A problem in the work stress literature is that the research identifies work-related stressors, yet interventions predominantly focus on individual factors. Further, understanding of the work stress process is guided by major theories that emphasise job design components. The research that has been inspired by these theories is possibly additionally compromised, because it is monolevel, focusing on individual perceptions of job design. Several researchers have called for multilevel theoretical models and research to explain the work stress process (Bliese et al., 2002; Sauter et al., 2002) and move beyond individual phenomenon as explanations for work stress.

The question must now be raised about the 'causes of the causes'. What are the conditions within organisations that give rise to prevailing work conditions? Here we propose a healthy conducive production model (Dollard \& Karasek, 2010), whereby production goals are considered as important as the psychological health of workers. If management is concerned about the balance of production goals and the psychological health of workers, and we expect that work conditions will also be balanced. Job demands will be manageable, because job resources are adequately supplied. We expect that organisational systems, policies, practices and procedures will reflect the production-health balance. The philosophy, values and actions of management give rise to what we call the PSC of an organisation.

PSC refers to a climate for employee psychological health and safety, and encompasses four inter-related principles: (1) the level of senior management commitment and support for stress prevention; (2) the priority management gives to psychological health and safety v. productivity goals; (3) organisational communication upwards and downwards in relation to psychological health and safety; and (4) the extent of participation and involvement by managers and workers in relation to psychological health and safety (Hall et al., 2010; Dollard, 2011). PSC is measured by aggregating perceptions of workers about these aspects to a unit or organisational level. In an Australian study of remote area nurses from 48 work units across the nation, assessed on two occasions ( $N=190$, Time $1 ; N=163$, Time 2), we found that between 15 and $24 \%$ of the variance in PSC was due to the unit to which the workers belonged (Dollard et al., n.d.). This shows that at a local level, management creates variation in PSC. This, is turn, has important implications for work conditions, health and productivity.

PSC contextualises the predominant work stress models by foregrounding working conditions; in effect, as a 'cause of the causes'. Senior managers play a significant role in allocating resources and establishing the tone of organisational climate (Flin, et al., 2000). Theoretically, in high PSC contexts where managers are concerned about worker well-being, they will ensure that the demands workers face is manageable. Therefore, PSC is an indicator of job demands which in turn predicts stress outcomes. This leads to an extended health erosion hypothesis of the JD-R theory (see Fig. 2).

As leaders are responsible for the way jobs are designed (Yukl \& Fu, 1999), in high PSC contexts managers will also ensure that workers have sufficient resources to do the job. Therefore, we expect a positive relationship between PSC and resources. Previous research shows the relationship between leadership for positive emotional climate and organisational performance, e.g. revenue growth (Ozcelik et al., 2008) and we suggest that this occurs via job resources and engagement. Accordingly, we propose an extended motivational path, wherein PSC is an indicator of job resources and, in turn, engagement and positive outcomes (see Fig. 2). A recent meta-analysis shows that the health erosion and motivational pathways are mechanisms via which demands and resources relate to safety outcomes (Nahrgang et al., 2011). Previous research also links work stress and medical errors (Jones et al., 1988). We expect, therefore, that PSC will precipitate these paths and is therefore a lead indicator of safety outcomes, accidents, errors and injuries, and also of quality of service and care.

Evidence is mounting about the importance of the PSC context in organisations. In relation to its 'cause of the causes' or possible 'preventative function', Dollard \& Bakker (2010) found that high PSC was longitudinally related to lower emotional demands, work pressure and increased skill discretion. In turn these demands and resources carried the effect of unit level PSC onto perceived psychological health status. These findings provide strong evidence for how PSC links to health outcomes; likely via policies, 


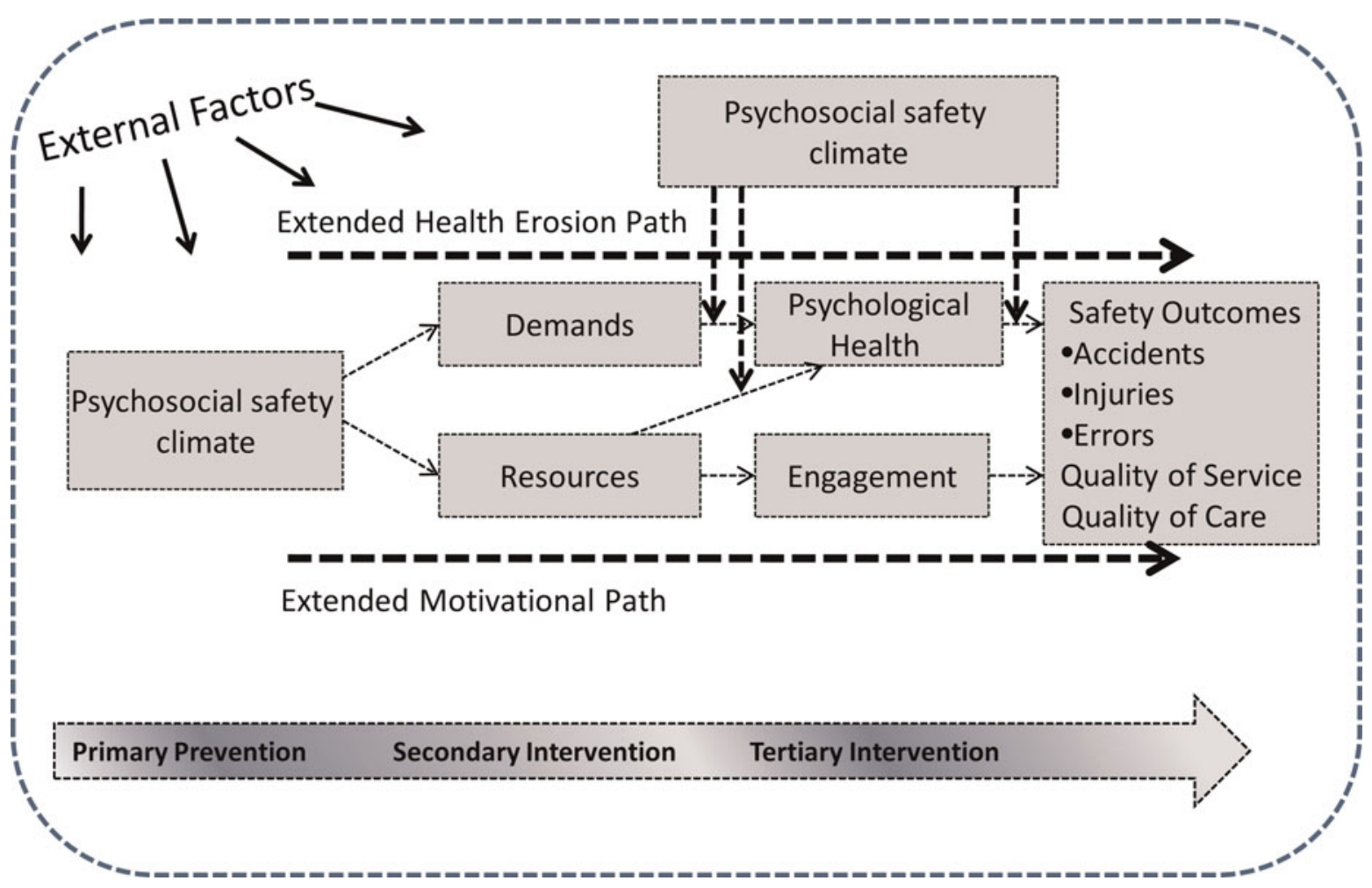

Fig. 2. PSC model of work stress in the health and community services sector. (A colour version of this figure is available online at http://journals.cambridge.org/eps)

practices and procedures that are implemented in relation to job design.

In relation to its amelioration or moderation function, PSC acts like a higher level support variable by providing the imprimatur for instrumental support (e.g. trained peer support) or by providing a context where workers feel comfortable utilising available resources to cope. Several studies have shown that the detrimental effect of demands on psychological health is moderated in the context of high PSC (Dollard \& Bakker, 2010; Law et al., 2011); and PSC at high levels moderated the effect of bullying on posttraumatic stress disorder (Bond et al., 2010).

Finally, in relation to its latency for hazardous behaviours, Law et al. (2011) found evidence that PSC acts as a latent pathogen for hazardous behaviours such as bullying and harassment. Organisations with high PSC are expected to have policies, practices and procedures regarding appropriate workplace behaviour that are strongly and consistently enacted. In the absence of policies and actions, bullying and harassment are tacitly condoned. In sum, PSC serves both a preventative and an ameliorative function in the development of work stress and is, therefore, an optimal target for primary and secondary intervention.

As we have been discussing, the aetiology of work stress is multifactorial in nature. A particularly useful framework for conceptualising these influences was proposed by the National Institute for Occupational Safety and Health (Sauter et al., 2002); the person at work is nested in multiple contexts (the external, organisational and work contexts), and each context exerts an influence on the health of the individual worker. Even beyond job design, and organisational influences such as PSC, factors external to the organisation may exert effects on the worker.

Public sector health agencies, in particular, respond to the vagaries of government policies and regulations. In recent years, the Australian public sector like many other sectors world-wide has been driven by economic rationalist policies that drive management systems to focus on efficiency and competition (Noblet et al., 2006). Managed care is a technique used in the US to deliver a more efficient health care system, and is influential now in countries including Australia. Research from the US shows that physicians working within this framework are generally less satisfied with their jobs (Linzer et al., 2000). They found among 2326 respondents that although there was more satisfaction with autonomy and administrative issues, physicians reported less satisfaction with resources, and relationships to staff and the community. They also reported less time for patients, and felt they needed more time, compared with physicians working in other 
practice settings. Evidence is building that these systems compromise professional-client relationships, and work pressure may lead to increased errors.

In conclusion, evidence suggests that levels of stress in the sector are high, and this coincides with high levels of risk (i.e. increasing emotional demands and work pressure). To help understand the stress process, we proposed a multilevel theoretical framework of work stress whereby PSC predicts work conditions, and triggers the health erosion and motivation pathways. Importantly, in the sector, this model could explain safety performance and quality of care outcomes. Beyond this, the impact of government policy, regulation and high performance systems in the sector seem to be taking their toll - this aspect needs urgent research attention.

\section{Declaration of interest}

Results reported in the paper are derived from projects funded by the Australian Research Council, NSW WorkCover Authority, SafeWork Australia, SafeWork SA, SA Health, Council of Remote Area Nurses of Australia, Northern Territory Department of Health and Community Services, Australian Government Department of Health and Ageing and Victoria WorkCover Authority.

\section{References}

Bakker AB, Demerouti E (2007). The job demands-resources model: state of the art. Journal of Managerial Psychology 22, 309-328.

Bakker AB, Schaufeli WB, van Dierendonck D (2000). Burnout: prevalence, risk groups and risk factors. In Mental Fatigue and Work (ed. I. L. D. Houtman, W. B. Schaufeli and T. Taris), pp. 66-82. Samsom: The Netherlands.

Belkic K, Landsbergis PA, Schnall PL, Baker D (2004). Is job strain a major source of cardiovascular disease risk? Scandinavian Journal of Work, Environment and Health 30, 85128.

Benveniste KA, Hibbert PD, Runciman WB (2005). Violence in health care: the contribution of the Australian Patient Safety Foundation to incident monitoring and analysis. Medical Journal of Australia 183, 348-351.

Bliese PD, Jex SM, Halverson RR (2002). Integrating multilevel analyses and occupational stress theory. In Research in Occupational Stress and Well Being (ed. P. L. Perrewe and D. C. Ganster), pp. 217-259. JAI Press: Amsterdam.

Bond SA, Tuckey MR, Dollard MF (2010). Psychosocial safety climate, workplace bullying, and symptoms of posttraumatic stress. Organization Development Journal 28, $37-56$.
Bowers L, Jeffery D, Simpson A, Daly C, Warren J, Nijman H (2007). Junior staffing changes and the temporal ecology of adverse incidents in acute psychiatric wards. Journal of Advanced Nursing 57, 153-160.

Brooks B, Staniford A, Dollard MF, Wiseman RJ (2010). Risk factors. Consequences, and management of aggression in health care environments. In Contemporary Occupational Health Psychology: Global Perspectives on Research and Practice (ed. J. Houdmont, and S. Leka), pp. 229-254. Chichester: Wiley Blackwell.

Demerouti E, Bakker AB, Nachreiner F, Schaufeli WB (2001). The job demands-resources model of burnout. Journal of Applied Psychology 86, 499-512.

Dollard MF (2011). Psychosocial safety climate: a lead indicator of work conditions, workplace psychological health and engagement and precursor to intervention success. In Managing Psychosocial Risks in the Workplace: The Role of Process Issues (ed. C. Biron, M. Karanika-Murray and C. L. Cooper). Routledge/Psychology Press (in press).

Dollard MF, Bakker AB (2010). Psychosocial safety climate as a precursor to conducive work environments, psychological health problems, and employee engagement. Journal of Occupational and Organizational Psychology 83, 579-599.

Dollard MF, Karasek R (2010). Building psychosocial safety climate: Evaluation of a socially coordinated PAR risk management stress prevention study. In Contemporary Occupational Health Psychology: Global Perspectives on Research and Practice (ed. J. Houdmont and S. Leka), pp. 208-234. Wiley-Blackwell: Chichester.

Dollard MF, La Montagne T, Shaw A, Blewett V, Caulfield N, Jordan J, Cooper CL (2006). Job stress: causes, impact and solutions in the health and community services sector: a literature review. In Job Stress: Causes, Impact and Interventions in the Health and Community Services Sector (ed. V. Blewett, A. Shaw, A. LaMontagne and M. F. Dollard). NSW WorkCover (http://www.workcover. nsw.gov.au/Publications/General/Research/job-stress_ causes_impact_interventions_in_health_community_ sector.htm). Sydney, Australia. Appendix 1-61.

Dollard MF, LaMontagne AD, Caulfield N, Blewett V, Shaw A (2007). Job stress in the Australian and International Health and Community Services Sector; a review of literature. International Journal of Stress Management 14, 417-445.

Dollard M, Opie T, Lenthall S, Wakerman J, MacLeod M, Rickard G, Knight S (2011). A multilevel model of Psychosocial Safety Climate As a Lead indicator of Job demands, control and support and psychological health. Work and Stress Research Group. University of South Australia.

Ecnotech (2008). The Cost of Workplace Stress in Australia. Prepared for Medibank Private, August 2008, Canberra.

Flin R, Mearns K, O'Connor P, Bryden R (2000). Measuring safety climate: identifying the common features. Safety Science 34, 177-192.

Hall GB, Dollard MF, Coward J (2010). Psychosocial safety climate: development of the PSC-12. International Journal of Stress Management 4, 353-383.

Jones JW, Barge BN, Steffy BD, Fay LM, Kunz LK, Wuebker LJ (1988). Stress and medical malpractice: organizational 
risk assessment and intervention. Journal of Applied Psychology 73, 727-735.

Karasek RA (1979). Job demands, job decision latitude, and mental strain: implications for job redesign. Administration Science Quarterly 224, 285-307.

Kessler RC, Aguilar-Gaxiola S, Alonso J, Chatterji S, Lee S, Ormel J, et al. (2009). The global burden of mental disorders: an update from the WHO World Mental Health (WMH) surveys. Epidemiologia e Psichiatria Sociale 18, 23-33.

Kumar S (2011). Burnout and psychiatrists: what do we know and where to from here? Epidemiology and Psychiatric

Sciences, (in press) 2011.

LaMontagne AD, Keegel T, Vallance D, Ostry A, Wolfe R (2008). Job strain - attributable depression in a sample of working Australians: assessing the contribution to health inequalities. BMC Public Health 8, 181-189.

Law R, Dollard MF, Tuckey MR, Dormann C (2011). Psychosocial safety climate as a lead indicator of workplace psychosocial hazards, psychological health and employee engagement. Accident Analysis and Prevention 43, 1782-1793.

Linzer M, Konrad TR, Douglas J, McMurray JE, Pathman DE, Williams ES, Schwartz MD, Gerrity M, Scheckler W, Bigby J, Rhodes E, and for the Society of General Internal Medicine (SGIM) Career Satisfaction Study Group (CSSG) (2000). Managed care, time pressure, and physician job satisfaction: results from the physician worklife study. Journal of General Internal Medicine 15, 441-450. doi: 10.1046/ j.1525-1497.2000.05239.x.

Marchand A (2007). Mental health in Canada: are there any risky occupations and industries? International Journal of Law and Psychiatry 30, 272-283.

Mayhew C, Chappell D (2003). The occupational violence experiences of 400 Australian health workers: An exploratory study. Journal of Occupational Health and Safety, Australia and New Zealand 19, 3-43.

McVicar A (2003). Workplace stress in nursing: a literature review. Journal of Advanced Nursing 44, 633-642.

Michie S, Williams S (2003). Reducing work related psychological ill health and sickness absence: a systematic literature review. Occupational and Environmental Medicine 60, 3-9.
Murray CJL, Lopez AD (1996). The Global Burden of Disease. WHO: Geneva.

Nahrgang JD, Morgeson FP, Hofmann DA (2011). Safety at work: A meta-analytic investigation of the link between job demands, job resources, burnout, engagement, and safety outcomes. Journal of Applied Psychology 96, 71-94.

Noblet A, Rodwell J, McWilliams J (2006). Organizational change in the public sector: augmenting the demand control model to predict employee outcomes under New Public Management. Work and Stress 20, 335-352.

Opie T, Lenthall S, Dollard M, Wakerman J, MacLeod M, Knight S (2010). Trends in workplace violence in the remote area nursing workforce. Australian Journal of Advanced Nursing 27, 18-23.

Ozcelik H, Langton N, Aldrich H (2008). Doing well and doing good; the relationship between leadership practices that facilitate a positive emotional climate and organizational performance. Journal of Managerial Psychology 23, 186-203.

Productivity Commission (2010). Performance Benchmarking of Australian Business Regulation: Occupational Health and Safety Research Report. Productivity Commission: Canberra.

Sauter SL, Brightwell WS, Colligan MJ, Hurrell Jr JJ, Katz TM, LeGrande DE, Lessin N, Lippin RA, Lipscomb JA, Murphy LR, Peters RH, Keita GP, Robertson SR, Stellman JM, Swanaon NG, Tetrick LE (2002). The Changing Organisation of Work and the Safety and Health of Working People. The National Institute for Occupational Safety and Health (NIOSH): Cincinnati.

Schaufeli WB, Bakker AB (2004). Job demands, job resources, and their relationship with burnout and engagement: a multi-sample study. Journal of Organizational Behavior 25, 293-315.

Siegrist J (1996). Adverse health effects of high-effort/ low-reward conditions. Journal of Occupational Health Psychology 1, 27-41.

Yukl G, Fu PP (1999). Determinants of delegation and consultation by managers. Journal of Organizational Behaviour 20, 219-223. 